\title{
Princípios de composição: descripções, narrações, cartas etc. por Guilherme do Prado (1895)
}

\author{
Components of composition: descriptions, narrations, letters, etc. \\ by Guilherme do Prado (1895) \\ Principios de composición: descripciones, narraciones, cartas etc. \\ por Guilherme do Prado (1895)
}

\author{
GERALDO INÁCIO FILHO ${ }^{1}$
}

\section{Resumo}

Os manuais escolares são utilizados no Brasil, para uso de professores e alunos desde fins do século XIX e, no decorrer do século XX firmaram-se como objetos ou utensílios da cultura escolar. Este artigo analisa um manual escolar produzido no Brasil em 1895 - Princípios de Composição por Guilherme do Prado. A investigação centra-se nas prescrições para o ensino da redação/composição na escola e procura ressaltar como o autor assimilou conhecimentos que contribuíram para fazer da composição/redação um saber escolarizado.

Palavras-chave: Manual escolar. Redação. Cultura escolar; História da Educação.

${ }^{1}$ Doutor em Educação pela Universidade Estadual de Campinas, com estágio de pós-doutorado concluído na Universidade de Lisboa. Professor do Programa de Pós-Graduação em Educação da Universidade Federal de Uberlândia. E-mail: gifilho@uol.com.br 


\begin{abstract}
School manuals to be used by teachers and students were established in Brazil in the late 19th century and were consolidated throughout the 20th century as objects or instruments of school culture. This article examines a school manual produced in Brazil at 1895 - Princípios de Composição, by Ghuilherme do Prado. This research focuses on the requirements for the teaching of writing at school and seeks to highlight how authors used knowledge that contributed to make writing a school knowledge.
\end{abstract}

Keywords: School textbook. Writing. School culture. History of Education.

\title{
Resumen
}

Los manuales escolares han sido utilizados en Brasil para uso de profesores y alunos desde finales del siglo XIX y se consolidaron a lo largo del siglo XX como objetos ou instrumentos de la cultura escolar. Este articulo analiza un manual escolar produzido en Brasil nel año 1895 por Guilherme do Prado. La investigación se centra en las prescripciones para la enseñanza de la escritura y procura ressaltar como el autor ha integrado conocimientos que contribuyeron a hacer de la escritura un saber escolarizado.

Palabras-clave: Manual escolar. Escritura. Cultura escolar. Historia de la Educación. 


\section{Introdução}

A História da Educação tem contribuído com a Pedagogia e com a Educação ao recuperar os processos educativos por que passam as nações ao longo do tempo, o que pudemos aquilatar ao longo de nossa trajetória acadêmica e educativa bem como pela nossa participação em eventos da área.

No âmbito do Brasil uma grande diversidade de núcleos e de linhas de pesquisa permitiu-nos a realização de congressos regionais, nacionais e supranacionais como modo de divulgar, dar a conhecer, a variada produção. Como exemplos podemos citar o Congresso de Pesquisa e Ensino de História da Educação em Minas Gerais (COPEHE), o EPECO (Encontro de Pesquisadores da Educação na Região Centro Oeste), o Congresso Brasileiro de História da Educação (CBHE), o GT-2 da AnPEd referente à História da Educação, o Congresso Ibero Americano de História da Educação, o Congresso Luso-Brasileiro de História da Educação e a ISCHE (International Standing Conference for the History of Education).

Os congressos ocorridos no país permitiram que uma variedade de pesquisas em diversas orientações teóricas, objetos, questões, fontes, levantadas em função da existência de uma plêiade de pesquisadores jovens e outros mais experientes que iniciaram a trilha ora em vias de se tornar uma autoestrada. Dentre as referidas fontes surge agora a dos "manuais pedagógicos".

[...] as diversas tentativas de tomar esses manuais escolares como fontes para a história da educação brasileira findaram por extrapolar uma mera descrição do processo de escolarização ou mesmo do cotidiano escolar, estabelecendo assim, relações de causalidade entre os processos sociais mais abrangentes e as particularidades da escolarização. $\mathrm{O}$ debruçar-se dos historiadores da educação sobre os manuais pedagógicos tem feito com que teias dissimuladas até então pela historiografia sejam reveladas, expondo articulações inusitadas entre ideias, processos, políticas e práticas educacionais (KULESZA, 2014, p. 330-331).

Podemos situar ainda a investigação acerca dos manuais escolares no âmbito da herança da Escola dos Annales, a qual minimizou a importância dos documentos oficiais em favor de uma variedade de novas fontes, de novas questões, de novos objetos e de novas metodologias.

A História Cultural, nessa perspectiva, toma a Escola em si, nas pesquisas sobre Instituições Escolares, na Cultura Escolar, nos utensílios didáticos, dentre eles os manuais pedagógicos, voltados ou não para o ensino escolar e a formação de professores e de estudantes de cepa diversa. Aqui fazemos eco com a professora Marta Maria Chagas de Carvalho (2007, p. 118) quando propõe:

Pondo ênfase nos suportes materiais da produção, circulação e apropriação dos saberes pedagógicos, essa modalidade de investigação abrange estudos sobre uma pluralidade de impressos de destinação pedagógica: livros didáticos, manuais 
escolares, imprensa periódica especializada em educação, bibliotecas escolares, coleções dirigidas a professores, etc. Nelas, essa multiplicidade de materiais impressos passa a ser objeto de um novo interesse. Livros, revistas, guias curriculares, programas, regulamentos, etc, não são mais, nessa perspectiva, que fontes de informação historiográfica. Passam a interessar como objeto, no duplo sentido de objeto de investigação e de objeto material, cujos usos, em situações específicas, se quer determinar. A materialidade desses objetos passa a ser o suporte do questionário que orienta o investigador no estudo das práticas que se formalizam nos seus usos escolares.

As concepções historiográficas de Roger Chartier e de Michel de Certeau balizam as proposições do presente trabalho e "implica tratar o livro como objeto cultural que, constitutivamente, guarda as marcas de sua produção, circulação e usos". Como utensílio modelizador das práticas em sala de aula e como suporte material de práticas de apropriação, quando se indaga sobre os indícios materiais das práticas dos sujeitos que dele se utilizaram (CARVALHO, 2007, p. 119-120).

O professor Wojciech Adrzej Kelusza no trabalho acima citado informa-nos que as bases para classificação de manual pedagógico são fornecidas pelos trabalhos de Vivian Batista da Silva (mestrado e doutorado dedicados ao assunto) orientada pela professora Denice Bárbara Catani. Vivian considera manuais pedagógicos os livros destinados ao ensino de disciplinas profissionalizantes dos currículos de instituições de formação docente, portanto, não se refere apenas aos livros destinados à formação de pedagogos, mas também relacionados às questões educacionais em geral, a didática, a metodologia, a prática de ensino e até da pedagogia (KULESZA, 2014, p. 331). Assim, as licenciaturas, de quaisquer áreas fornecem ou podem fornecer fontes para a História da Educação.

É ainda Vivian Batista da Silva quem caracteriza os manuais pedagógicos como obras que se apropriam de conhecimentos variados em "escritos aparentemente claros e concisos, ora para explicar questões ligadas à escola, ora para fundamentar recomendações a serem seguidas pelos professores em situação de aula" (SILVA, 2003, p. 46).

[...] Trata-se de representações entendidas no sentido sugerido por Chartier (1991), ou seja, esquemas que dão sentido a uma realidade. No caso, define-se aquilo que é importante para constituir uma cultura profissional docente, o que apresenta variações ao longo do tempo, como já deixa entrever a análise de conjunto de obras e autores utilizados. Outro indício a ser considerado nesse processo refere-se aos temas privilegiados, os quais podem ser identificados desde os títulos e índices dos livros. Num primeiro momento situado entre os anos 1930 até 1946, observa-se uma atenção voltada para a explicação dos postulados da Escola Nova. A partir de finais dos anos 1940, diferentemente, as questões metodológicas começam a receber um espaço notável, estando o objeto de interesse na maior parte dos capítulos desenvolvidos ao longo das páginas. Essa tendência acentua-se nas décadas de 1960 e 1970, com as descrições sistemáticas a respeito de técnicas pedagógicas. Tais 
mudanças podem ser descritas da seguinte forma: 1930 a 1946: entusiasmo pelo movimento escolanovista; 1947 a 1959: a proposição de metodologias a serviço da eficiência das atividades pedagógicas.

\section{Do Objeto}

O objeto de nosso estudo é um livro denominado Princípios de Composição: descripções, narrações, cartas, etc. Na capa aparece a informação que foi editado "segundo o programa do governo", sem se referir a qual governo (federal, estadual ou municipal) e que se trata da terceira edição "correcta e augmentada". O autor da obra é Guilherme do Prado. A Editora é a Livraria Clássica de Alves e C. e a referida edição é datada de 1895. A Editora referida possui endereços no Rio de Janeiro (Rua Gonçalves Dias, 46) e em São Paulo (Rua da Quitanda, 9)².

O Regime Republicano implantado no Brasil em 1889 deveria preocupar-se em converter o súdito em cidadão. A primeira reforma de ensino data de 1891 e ficou conhecida como Reforma Benjamin Constant. A antiga província, agora Estado de São Paulo inovava propondo os grupos escolares como contraponto às escolas isoladas do período imperial, ainda reproduzindo, de certa forma, as escolas régias do período pombalino.

Figura 1: Foto da página de rosto por Geraldo Inácio Filho.

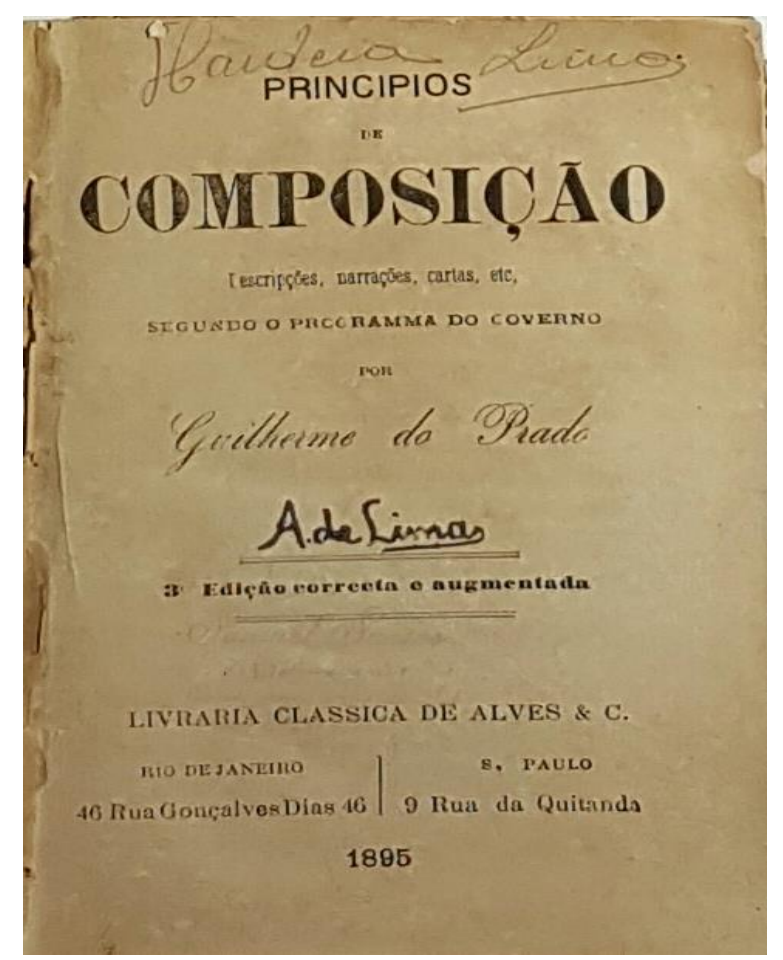

Fonte: Acervo do Núcleo de Pesquisas em História e Historiografia da Educação (NEPHE/UFU).

\footnotetext{
${ }^{2}$ A grafia do original será mantida sempre que possível.
} 
O positivismo comteano fez-se presente entre os republicanos desde antes da proclamação da República. Tanto que o dístico de nossa bandeira nacional estampa "ordem e progresso" como marca precisa dessa influência francesa.

O Índice aparece ao final do Manual, após a página 140, mas as páginas de seu conteúdo não foram numeradas em sequência. Possui seis partes a saber: 1) Preliminares; 2) primeira parte; 3) segunda parte; 4) terceira parte; 5) quarta parte e 6) quinta parte.

Estranhamente não há introdução, nem prefácio, nem considerações finais/conclusões. As Preliminares (p. 3-15), por se tratar de um manual de composição tem como assunto a forma dos objetos: linha recta, linha curva, ângulo, polygono, triangulo, quadrilatero, quadrado, reactangulo, circumferencia, oval, ellipse, cubo, prisma, cylindro, tubo, pyramide, cone, esphera.

A seguir trata das dimensões dos objetos: comprimento, largura, espessura (grossura); das cores, do sabor (ou gosto); dos cheiros; do brilho (baço, desluzido, empanado, fosco, transparente ou diaphano, luminoso, opaco. A consistência dos objetos (crystaes, moléculas, poros, cohesão, solido, liquido, gasoso). Movimento e repouso - corpos brutos ou inanimados ou inertes.

Relação de logar, posição, duração e tempo. Ideias de interior (dentro), exterior (fora), superior (em cima), inferior, anterior (na frente), posterior (detraz), lateral (do lado), ante, pre, historico, antigo, moderno, contemporaneo, recente, septentrional, meridional, oriental, occidental, local, exótico, indigena, estranho, instante, segundo, minuto, hora, dia, semana, mez, trimestre, semestre, anno, lustro, século, relogio, clepsydras.

Pode-se supor que uma das tarefas do professor seria definir, decodificar os conceitos aqui referidos, posto que a maioria deles estão apontados, mas não definidos. Como no exemplo:

A idea de espaço de tempo exprime-se por meio das seguintes palavras: instante, segundo, minuto, hora, dia, semana, mez, trimestre, semestre, anno, lustro, seculo. Para medir o tempo ha machinas chamadas relogios. Os antigos mediam o tempo por meio de apparelhos muito menos exactos, chamados clepsydras $(\mathrm{p} .15)^{3}$.

A primeira parte (p. 17-39) é dividida em capítulos (sete) tão pequenos que os três primeiros cabem em uma única página (17). Tais capítulos não se apresentam no índice, mas apenas no interior da parte I. O primeiro deles define composição: "arte que ensina a exprimir os pensamentos por meio da linguagem". Caracteriza proposição, período composto, parágrafo, composição (tema, ensaio). O seguinte trata do período simples, enquanto o terceiro define o período complexo, propondo três baterias de exemplos. Na página 19 situase o capítulo IV o qual trata de definir período composto, cuja exemplificação dá-se com citações do Marquez de Maricá, de Alexandre Herculano e do Padre Antonio Vieira.

$\mathrm{O}$ capítulo $\mathrm{V}$ - combinação e conversão das proposições (ampliação e contracção) com exemplos (p. 20). Capítulo VI - da disposição dos complementos e das proposições -

\footnotetext{
${ }^{3}$ Doravante nos referiremos à obra em análise apenas pela página citada.
} 
$\mathrm{Na}$ formação dos períodos deve-se evitar que as proposições que se succedem, sejam de um só typo. Os períodos externos devem conter umas proposições simples e outras complexas ou compostas. Quando ao mesmo verbo se juntam complementos de diversa natureza, devem-se collocar os mais extensos depois dos menos extensos, e mesmo é conveniente muitas vezes collocar algum antes do verbo (p. 21).

Acompanham duas baterias de exemplos com citações de Alexandre Herculano e Marquez de Maricá.

O capítulo VII (p. 22-25) trata da variedade na estructura das proposições e dos períodos - syntaxe, phraseologia, voz passiva, voz activa, declaração, interrogação, affirmação, exclamação, forma directa, forma indirecta. O paragrapho - é caracterizado. Em seguida são expostas suas qualidades: unidade, ligação, variedade. Nos exemplos são utilizadas citações de Alexandre Herculano, Antonio Feliciano de Castilho, R. Lobo e Latino Coelho.

À página 26 encontramos uma Nota Preliminar (Aos professores) com informação no rodapé que foi "Extrahida da grammatica do $2^{\circ}$. anno de J. Ribeiro. Ei-la na íntegra:

Qualquer que seja a variedade de assumptos a redigir e quaesquer que sejam as difficuldades que se apresentem ao espirito dos alumnos, é fácil de ver-se que toda redacção pressupõe o uso apropriado de dous princípios:

a) A invenção.

b) A elocução.

Pela invenção o alumno deve aprender a analysar os objetos e as cousas, achar-lhes os attributos - grandeza, côr, utilidade, belleza, etc., exprimir todas as sensações materiaes ou impressões Moraes que os objectos e as cousas despertam.

Quando a faculdade de analyse se acha bastante desenvolvida no espirito do alumno, só lhe resta afinal redigir seus pensamentos ou compôr a elocução.

A elocução é um effeito espontaneo e regular, porque ninguem pensa que não fale. A phrase está naturalmente feita no espirito e a unica difficuldade nessa parte consiste em coordenar as phrases de modo correcto e grammatical, e dar às palavras as variações que ellas comportam de genero, numero, tempo e pessoa, sempre de accôrdo com o melhor uso. O melhor uso da elocução é o que vem consignado na grammatica.

A questão é toda pratica; pouco valem as regras; os exercicios valem tudo.

No interior do referido capítulo VII o autor discorre sobre invenção, elocução correta e informa a fonte do seu "methodo de redacção" utilizado: 
[...] Consultamos com proveito varios auctores inglezes, francezes e italianos que se occuparam do assumpto, mas entre todos os mestres preferimos T. Frieh, que nos pareceu o mais claro, o mais simples, e o mais pratico de todos os expositores. Apropriando-nos dos exemplos desse illustre mestre, fizemos as alterações necessarias á adaptação das escolas brasileiras, escolhendo os assumptos mais communs á nossa vida local.

Também reduzimos os exercicios ao numero que nos pareceu indispensavel para dar idea clara do methodo a seguir-se. Todos sabem que, nesse particular, os exercicios escolares se fazem sob a immediata inspiração dos mestres e não sob a cópia de grammaticas ou de outros quaesquer livros (p. 27).

Prossegue apresentando sua convicção de que no futuro a gramática ou código das regras da língua seria se não eliminada, pelo menos diminuída de importância no curso geral nos estudos elementares. Segundo ele a gramática seria importante para ensinar a falar e a escrever certo, como o é um código penal ou um catecismo para fazer os homens virtuosos.

Com ele concordamos que a criança não sabe gramática quando aprende a falar. Todavia, para escrever bem, para comunicar-se com correção ela é indispensável. É desagradável ler textos cujos autores expressam-se com incorreções gramaticais, erros de concordância e de ortografia. Guilherme do Prado (p. 28) prossegue na defesa de seu teórico inspirador:

Os exercicios de T. Frieh têm a vantagem de reunir ao ensino grammatical a qualidade de equivalerem a verdadeiras lições de cousas. Nem outro podia ser o resultado pratico do seu methodo, atendendo-se a que a faculdade e analyse só póde desenvolverse pela observação exacta dos phenomenos e das cousas.

Os exercicios que escolhemos, pódem ser considerados simples modelos e como taes pódem servir de base à preparação de outros, análogos na idea e nos intuitos, variando-se o assumpto como convier. O essencial é, aqui como no mais, evitar-se a decoração de regras, definições e teorias e substituir-se essa pesada bagagem quasi inutil, imposta á memoria, pela acquisição racional de noções e conhecimentos indispensáveis.

Para o nosso autor os exercícios de invenção deveriam ter como finalidade o desenvolvimento, no aluno, da capacidade de análise pelo exame dos atributos e das particularidades dos objetos. A progressão deveria ir dos mais simples aos mais complexos, enquanto os exercícios de elocução deveriam ensinar a redação correta do pensamento, segundo as regras da gramática. A avaliação, também aqui, deveria ser progressiva, partindo de variações simples (número, gênero, tempo, etc.) às variações mais complexas como sintaxe e concordância (p. 29). 
Como se pode observar, o autor e seu inspirador inglês, não são contrários a ensinar-se as regras gramaticais, a não ser que se fique somente na cobrança delas recorrendo apenas à capacidade de memorização do educando. Ela, a gramática, deve ser utilizada na medida que contribua por uma redação correta. Então, o Manual é configurado, no dizer de Marta de Carvalho, como caixa de utensílios

[...] se organiza segundo a lógica de fornecer ao professor 'coisas para usar' na sala de aula, compondo um programa curricular: uma poesia, aqui, um canto ali, uma estorinha lá. Nessa lógica, o manual é composto como impresso cujos usos supõem regras que não necessitam de explicitação, sendo dadas como regras culturalmente compartilhadas. Nesse sentido, a lógica que preside a composição desse tipo de manual, que circulou nas últimas décadas do século XIX e primeiras do século XX deve ser buscada no campo normativo das concepções pedagógicas que lhe são contemporâneas e que prescreviam a boa arte de ensinar como boa cópia de modelos. Assim, o impresso como caixa de utensílios se organiza a partir do suposto de que o seu próprio código de leitura está dado em outra parte; no caso, no conjunto de regras culturalmente enraizadas que componham a crença no impacto renovador do que era proposto então como pedagogia moderna. Decifrar esse código de leitura permite explicitar as regras de uso prescritas para os materiais impressos na revista, entendendo-se, deste modo, como nela se dispõe e se organiza essa pedagogia que se propõe a modelar a arte de ensinar (CARVALHO, 2007, p. 123-124).

Prossegue o autor com exercícios acerca de explicar diferenças entre aves e mamíferos ou entre naturezas animal, vegetal e mineral ou entre peixes e répteis. Após um dos exercícios propõe ao professor corrigir prováveis erros lembrando que a baleia é um mamífero e não um peixe e que o escorpião não é um réptil e sim um anelado (p. 30).

Os exercícios seguintes consistem em aplicar os nomes (violeta, batata, feijão, fava, capim, trevo, milho, amendoim, chá, café, caju, castanha do caju, farelo, alfafa, nabo, pessego, cenoura, couve, giló (sic), cravo, canela, cortiça, mandioca, côco, maçã, caroba, salsa, trigo, feno) denominação conveniente de flor, fruto, raiz, folha, casca, legume ou forragem (Modelo: a rosa é uma flor).

No exercício seguinte o aprendiz deveria dispor em uma coluna, as coisas naturais e em outra as coisas fabricadas: o sol, a moeda de ouro, a madeira, a prata, o ouro, a casa, a mangueira, a jabuticaba, a loja, o homem, a gordura, o arado, a caneta, a pena do pato, a chuva, o vinho, a uva, o queijo, o leite, a estátua, o mármore, o cimento, a estrada, o rio, a floresta, a chave, o açúcar, a lã, a seda, o pergaminho, as luvas.

A seguir trabalha os adjetivos pátrios segundo o modelo: Quem nasce em França é francês. $\mathrm{O}$ autor alerta que os nomes grifados apresentam maior dificuldade devendo, portanto, o professor insistir nelas. Estavam grifados no original: Hungria, Polonia, Rumania, 
Bélgica, Estados Unidos, Buenos Aires, Rio de Janeiro, Córsega, Provença, Terra do Fogo (fuegano), Patagônia, Nápoles (p. 31).

Passa-se à conjugação de verbos onde há uma coluna da esquerda um verbo no subjuntivo e na coluna da direita uma frase onde no lugar do verbo conjugado aparecem reticências para o educando apor o verbo no seu tempo e conjugação corretos. (Exemplo: subir --- Luiz XIV ao trono em 1643).

Há exercícios para variar o gênero (masculino e feminino); quanto aos adjetivos os graus comparativo e superlativo, formação de plural, sintaxe geral (sujeito simples e sujeito composto); formação do objeto (simples e composto), conjunções coordenadas (mas, ou, e) e exercício para corrigir vícios de sintaxe cometidos entre brasileiros (p. 32-34).

O título da página 35 é "Composição Livre". Trata da importância de se multiplicar e variar as formas tanto quanto o exijam as práticas de ensino e desde que os alunos se achem familiarizados com a gramática deve-se tentar composição ou redação de assuntos mais complicados. Lembra que o primeiro cuidado dos mestres seria fornecer o esqueleto, as noções mais importantes sobre os quais deve versar a redação do aluno, tornando assim a redação uma simples coordenação fundada sobre as noções simples fornecidas pelo professor. Expõe alguns modelos sobre os quais deveriam se basear os temas para redação (A Escola; a Cidade; a Igreja; Os animais domésticos; Outros animais domésticos; A loja de um joalheiro; Os insetos; O jardim; Uma casa; O ano; O dia; A roça; A flor; O mar). Nosso autor orienta o professor:

Neste exercício como nos outros que se seguem, fornecem-se apenas noções isoladas. $\mathrm{O}$ alumno deve reunil-as em phrases e coordenar as phrases segundo a syntaxe, e com a pontuação devida (p.35).

Para cada um deles propõe um "esqueleto" para a redação, apresentando os tópicos que deveriam ser tratados como nos exemplos abaixo:

\section{A ESCOLA}

O edifício. A sala onde se ensina. A classe. As carteiras. Os alumnos. () mestre. Os objetos da escola: quadros muraes, mappas, globos, a pedra, o contador mecanico, as pennas, o papel, o tinteiro. Os livros. Os cadernos. Cuidados que devem ter com taes objectos. Para que serve o globo. As horas de lição. O tempo de ensino. A sahida. As ferias. Os premios; as boas notas. Os máos alumnos.

\section{A ROÇA}

A viagem por terra. $\mathrm{O}$ embarque em caminho de ferro. $\mathrm{O}$ trem expresso. A chegada á estação. A viagem a cavallo. As estradas. As montanhas. A floresta virgem. A roça. O cafezal. O cannavial. Os instrumentos da agricultura: utensílios, animaes. Os estrumes. O amanho. A colheita ou safra. O transporte dos productos. 
Para concluir esta primeira parte o autor assim se expressa:

Concluimos aqui os exemplos que apresentamos como simples modelos de suggestões aos alumnos.

É claro que elles não podem ser convenientemente desenvolvidos sem o auxilio dos mestres; mas cremos que não tanto a quantidade mas a variedade dos exercicios é o primeiro e mais seguro passo no ensino da composição (p. 39).

Pode-se inferir pelas sugestões do autor que ele vivia em uma sociedade agrária tal a importância dos temas referentes às coisas do mundo rural. Naqueles finais do século XIX a maior parte da população vivia no meio rural, tendo a cidade como lugar das atividades festivas, do cumprimento das obrigações cívicas, as quais apenas às elites competiam. Os temas também permitem-nos detectar grande influência das "coisas da roça" na vida da escola e da coletividade, o que se espelha sempre no interior daquela, a qual deve preparar os miúdos para o convívio da sociedade na qual a escola se insere.

Evidente que se dispensa dizer, nos períodos de intensa dominação de classe, ou nos períodos em que a hegemonia se manifesta de modo peremptório, isso se dá de forma "pacífica" e ordeira, significando a aceitação passiva ou imposta do mando. Nos períodos, como o que vivemos, quando a hegemonia é posta em questão, torna-se claro o fracionamento da liderança e a disputa pelos domínios das instituições políticas, sociais e, principalmente, as geradoras da riqueza nacional.

\section{Segunda parte}

Inicia-se esta secção (p. 41-46) pela definição da "descripção". Prossegue com observações destinadas ao professor:

Nas descripções de animaes os alunos devem ter em vista as seguintes sugestões:

Apparencia geral, nome, tamanho, fórma, pello, e côr.

PARTES. - Cabeça e suas partes, pescoço, pernas, pés, dedos (e em alguns as azas, a cauda, as orelhas, os cornos, focinho ou tromba).

\section{COSTUMES.}

\section{Utilidade (usos).}

Descreve um ganso, em seguida como se deve descrever uma "paysagem". Depois, um exemplo de descrição de paisagem. Segue orientação para descrição de uma casa seguida de exemplo. Descrição de uma pessoa: modelo e exemplo com "Maria da Escossia". 


\section{Terceira parte}

Essa parte (p. 47-68) recebe o título de "MODELOS SOBRE DIVERSOS ASSUMPTOS”. Sendo o primeiro exemplo "O jardim do campo da Acclamação", seguido do "A estrada da Tijuca", depois "Uma inundação", "Fazenda de Campos Novos" (Teixeira de Souza); "O pampa"; "Descripção de uma tempestada em Terra" (Frei Luiz e Souza); "Descripção dos trajos das serranas de Castro Laboreiro"; "Descripção do physico e moral de Affonso de Albuquerque" (atribuída a Barros tão somente isso); "Descripção do sitio da serra de Ibiapaba" (Padre Antonio Vieira); "Descripção do Rio Amazonas" (Frei Caetano Brandão); "Descripção do physico e moral d'El-Rei D. João II" (autoria de Garcia de Rezende); "Descripção dos arrabaldes de Guzarate" (Tristão da Cunha); "Tempestade e Bonança" (Teixeira e Souza); "O fogo do campo" (Manuel Antônio de Almeida); “A serra de Paranapiacaba" (Salvador de Mendonça); "O ferro".

\section{Quarta parte: da narração}

No próximo tópico (p. 69-87) o autor caracteriza narração como uma exposição de fatos reais ou imaginários que devem ser escritos na ordem que se sucederam, acompanhados das circunstâncias e observações que a eles se referem. Recomenda não sair do assunto para narrar outra história, pois isso violaria a Lei da Unidade. Propõe que a narração de pequenos incidentes e descrições de pessoas ou coisas podem utilizados apenas para embelezar ou aumentar o interesse da narração principal (p.69).

Se o escritor cometer algum erro quanto a colocação dos principais acontecimentos viola a lei da seleção e a lei da perfeição se omitir um ou mais dos acontecimentos principais. E prossegue

Se os incidentes de uma historia não forem narrados na ordem
natural, de modo que o leitor os possa compreender
facilmente na ordem em que estão dispostos, está violada a lei
do Methodo; comtudo não é necessario que os acontecimentos
sejam sempre narrados na ordem de tempo em que ocorreram.
Para que uma narração seja perfeita, é indispensavel prestar
tanta attenção ao acontecimento principal e ás circumstancias
que lhe estão subordinadas, como aos outros acontecimentos e
suas circumstancias: desse modo evita-se violar a lei da
Symetria (p. 70).

A seguir apresenta os seguintes modelos de narração: "Teima de um poeta" (A. F. de Castilho); "O velho guerreiro" (José de Alencar); "Chegada a Santarém" (Visconde de Almeida Garret); "Conquista da Peninsula por Tarik e Musa" (Alexandre Herculano); "Narração do feito heroico de Nuno Gonçalves" (Alexandre Herculano) (p.87). 


\section{Quinta parte: cartas}

Na página 87 findam as narrativas e se iniciam as cartas (p. 87-139) dos mais diversos teores. O título cartas traz várias orientações acerca de como se deve escrever uma carta. Deixa fora as cartas comerciais. Atributos que uma carta deve possuir: simplicidade, temperança, naturalidade e propriedade (a quem, por que, como?).

As cartas apresentadas como modelo levam os seguintes títulos: do filho para sua mãe; de um filho a seu pae; a um primo pedindo-lhe dinheiro; de um filho a um pae sobre a carreira a seguir; de pae a filho; carta pedindo uma nota para um trabalho litterario; carta de Castilho a Mont'Alverne sobre assumpto litterario; resposta à carta precedente; carta de D. Pedro V ao Duque da Terceira; carta de A. Herculano sobre a cultura do cardo e seu preço; carta do mesmo, remettendo uns queijos; carta de um amigo sobre diversos assumptos; carta dando varias noticias; carta de recommendação; carta de offerecimento de serviços; carta de pezames; outra sobre o mesmo assumpto; carta em resposta a uma de pezames; carta a um irmão; carta a uma filha; carta a uma prima; carta a uma irmã; carta a um amigo dando-lhe os parabens; carta a um amigo; carta de felicitações; resposta; carta de um soldado ao seu general; carta de um general a um official; carta a um juiz; carta de agradecimento; carta de parabens pelo nascimento de um filho; carta offerecendo um livro; resposta á carta precedente; carta participando a morte do pae pedindo o emprego que elle occupava; resposta á carta precedente; outra; carta de agradecimento a um coronel; carta agradecendo tel-o defendido de uma calumnia; carta devolvendo um livro emprestado; carta remetendo dinheiro; carta de recommendação; carta recommendando um filho; carta dando noticias de uma viagem; carta agradecendo a hospitalidade recebida; carta queixando-se de não receber resposta ás cartas escriptas; carta pedindo desculpa; carta justificando-se de uma falta; carta a um pae no dia de seus annos; carta a uma mãe no dia de seus annos; carta a uma amiga a quem remete fructas; resposta á carta precedente; carta de um militar a seus paes; carta a um amigo de quem não ha noticias; carta a um amigo; carta de agradecimento; carta de Cícero a sua mulher.

A página 139 finaliza o livro após uma carta atribuída a Cícero (O romano) e endereçada à sua mulher. Como se pode ver no parágrafo anterior a esse, há uma profusão de exemplos ou modelos de cartas, para todos os fins. O manual não traz conclusão, considerações finais, nem nada que lembre o que hoje serve para fechar nossos trabalhos acadêmicos. Finaliza com o índice cujas páginas são numeradas em algarismos romanos (p. I-IV).

\section{Considerações finais}

Ao apagar das luzes do século XIX uma nova cultura escolar entrava em voga em todo o mundo ocidental. Trata-se do que se convencionou denominar Escola Nova, que valorizava a experiência da criança em detrimento da memorização pura e simples, descontextualizada da vivência do aprendiz, além de estimular sua criatividade e a prática de atividades significativas para a criança na escola e fora dela.

O manual, no referido contexto serviu a tais propósitos, especialmente no que respeita à formação do professor para essa escola em tempos de mudança. A educação e o ensino em 
particular foram vistos como uma grande oportunidade para trazer para o interior da escola os conhecimentos/saberes disponibilizados pela ciência, então valorizada como eixo de uma sociedade burguesa oposta àquela sociedade medieval centrada na religião.

Assim como soe ocorrer com o processo educativo em qualquer sociedade, à escola cabe transmitir aos educandos os valores e saberes necessários à perpetuação dessa mesma sociedade. Quando a escola se propõe a modificar tais valores a reação é imediata, como se pode notar nos dias de hoje, especialmente nos debates entre escola sem partido, gênero, etc.

A escola de fins do século XIX no Brasil tinha como pontos fortes ensinar a ler, escrever e contar. Pois bem, nosso manual em estudo refere-se justamente à arte de bem escrever. Por isso é atípico, posto que grande parcela dos até então estudados tratam da leitura e não da redação.

O autor busca sua fonte de inspiração em autor inglês (T. Frieh), enquanto grande parte da literatura alusiva ao tema inspira-se em textos franceses, conforme se pode aferir nos trabalhos de Marta Maria Chagas de Carvalho (Uma biblioteca pedagógica francesa para a Escola Normal de São Paulo (1882): livros de formação professional e circulação de modelos culturais) e Thabatha Aline Trevisan (Manuais de Pedagogia franceses para formação de professores no Brasil (1851-1959)). Nossos primeiros republicanos se abeberaram no modelo francês de escola e nos ensinamentos de Augusto Comte, assim como nosso modelo republicano ora se inspirava na França ora nos Estados Unidos da América.

Guilherme do Prado procurou adaptar o texto original às condições e à cultura do Brasil daquela época. Apresentou exemplos de escritos produzidos por literatos de renome quer sejam brasileiros ou portugueses, como exemplos: Almeida Garret, Padre Antônio Vieira, Alexandre Herculano, etc. Há no texto grande ênfase na narração, embora não se descuide da descrição.

Procuramos apresentar uma bibliografia referente ao assunto, que possa levar nossos alunos a se iniciarem ao tema com alguma retrospectiva contempladora de grandes nomes da nossa História da Educação enquanto produtores de textos sobre os manuais pedagógicos, os quais, pode-se notar, sofreram uma grande transformação, seguindo o percurso do nosso processo de escolarização ao longo do século XX (Cf. CARVALHO, 2007a; TREVISAN, 2010 e SILVA, 2006).

Durante a segunda metade do século passado as pesquisas em História da Educação no Brasil elevaram-se em quantidade e qualidade a patamares dignos de figurar junto aos equivalentes na Europa e na América.

Essa grande produção de textos de qualidade, e não poderia ser de outra forma, tornou os manuais nada mais que objetos de estudo para a História. Nossos pesquisadores os têm utilizado com muita seriedade no sentido de se recuperar as representações de educação e ensino presentes nos textos analisados.

Assim sendo, esse manual de Composição permite perceber o interesse do autor em não se afastar do que se fazia e se pensava no mundo, ao mesmo tempo que levava em consideração nossa realidade nacional. Nisto, talvez, consista a relevância do presente texto aqui inserido neste Dossiê acerca dos Manuais Pedagógicos antigos. Oxalá seja de alguma utilidade! 


\section{Referências}

BASTOS, Maria Helena Câmara. Um manual e suas diferentes apropriações. "Noções de História da Educação" de Theobaldo Miranda Santos (1945). www.sbhe.org.br/novo/congressos/cbhe5/pdf/57.pdf. Acesso em 30 mai. 2017.

CARVALHO, Marta Maria Chagas de. Manuais de Pedagogia, materialidade do impresso e circulação de modelos pedagogicos no Brasil. Revista Colombiana de Educación, n. 52, janjun 2007a, p. 114-135.

Uma biblioteca pedagógica francesa para a Escola Normal de São Paulo (1882): livros de formação professional e circulação de modelos culturais. In: BENCOSTA, Marcus Levy (org). Culturas Escolares, saberes e práticas educativas: itinerários históricos. São Paulo: Cortez, 2007b, p. 17-40.

CATANI, Denice Bárbara \& SILVA, Vivian Batista da. Memória e História da profissão dos professors: as representações sobre o trabalho docente nos manuais pedagógicos. Educação em Foco, Juiz de Fora, 2009. Disponível em: http://www.ufjf.br/revistaedufoco/files/2009/10/3430-2-Ana-Maria_7_1.pdf. Acesso 30 mai. 2017.

CERTEAU, Michel. A invenção do quotidiano: 1 . Artes de fazer. Trad. Ephraim F. Alves. Petrópolis: Vozes, 1994.

CHARTIER, Roger. O mundo como representação. Estudos Avançados, São Paulo: USP, vol. 5, n. 11, 1991, p. 173-191. Trad. Daher...

CUNHA, Maria Teresa Santos. A mão, o cérebro, o coração. Prescrições para a leitura em manuais escolares para o curso normal (1940-1960/Brasil-Portugal). Revista Brasileira de História da Educação, vol. 13, n. 3 (33), Campinas, set-dez 2013, p. 285-309.

GATTI JR., Décio. Dos antigos manuais escolares aos modernos livros didáticos de História do Brasil: dos anos sessenta aos dias atuais. Ícone, vol. 6, n. 1, Uberlândia, jan-jun 2000, p. 97-116.

KULESZA, Wojciech Andrzej. História da Pedagogia no Brasil: contribuição das pesquisas centradas em manuais de ensino. Revista Brasileira de Estudos Pedagógicos. Vol, 95, n. 240, Brasília, maio-ago 2014, p. 328-345.

MONTEIRO, Augusto. Um manual de educação cívica e um catecismo republican: Portugal nossa Terra. In: MOURÃO, Alda e GOMES, Angela de Castro. A experiência da Primeira República no Brasil e em Portugal. Coimbra: Imprensa Universitária de Coimbra. Disponível em: https://digitalis-dsp.uc.pt/bitstream/103162/35877/1/A\%20experiencia_ artigo10.pdf?In=pt-pt. Acesso 30 mai. 2017.

OSSENBACH, Gabriela \& SOMOZA, Miguel (orgs). Los manuales escolares como fuentes para la Historia de la Educación en América Latina. Madrid: UNED, 2001. 
PINTASSILGO, Joaquim. Os manuais de Pedagogia no primeiro terço do século XX: entre a tradição e a inovação. In: CARVALHO, M. M. C.; MOGARRO, M. J. \& PINTASSILGO, J. História da Escola em Portugal e no Brasil: circulação e apropriação de modelos culturais. Lisboa: Educa, 2005, p.

SILVA, Vivian Batista da. Leituras para professors: apropriações e construção de sabers nos manuais pedagógicos brasileiros escritos pelos "católicos" (1870-1971). Cadernos de História da Educação, vol. 2, Uberlândia, 2003, p. 51-58.

Uma história das leituras para professores: análise da produção e circulação de saberes especializados nos manuais pedagógicos (1930-1971). Revista Brasileira de História da Educação, n. 6, Campinas, jul-dez 2006, p. 29-57.

TREVISAN, Thabatha Aline. Manuais de ensino de Pedagogia no Brasil: um instrumento de pesquisa (1874-1959). V Congresso Brasileiro de História da Educação, Aracaju, 2008, Anais eletrônicos. CD-ROM.

Manuais de Pedagogia franceses para formação de professors no Brasil (1851-1959).

VIII Congresso LusoBrasileiro de História da Educação, São Luís, 2010, Anais Eletrônicos, CD-ROM. 